\title{
OLAP Berbasis Spasial pada Data Transaksi Booking di "Koperasi Sehati” Depok
}

\author{
Muhammad Asna Faqih dan Budi Setiyono \\ Departemen Matematika, Fakultas Matematika, Komputasi dan Sains Data, \\ Institut Teknologi Sepuluh Nopember (ITS) \\ e-mail:budi@matematika.its.ac.id
}

\begin{abstract}
Abstrak-Koperasi Sehati Depok memiliki data transaksi booking yang diantaranya berisi data-data pembiayaan. Datadata ini diolah untuk mendapatkan berbagai informasi yang dapat digunakan sebagai bahan analisis. Informasi tersebut dibuat pelaporan agar pengguna khususnya bagian manajemen dapat lebih memahami data-datanya. Salah satu metode analisis dalam memperoleh berbagai informasi adalah menggunakan metode OLAP. Seiring dengan berkembangnya koperasi maka diperlukan model pelaporan yang lebih detail dan dapat dilihat dari berbagai sudut pandang. Selain itu, pelaporan terkait spasial juga sangat dibutuhkan untuk mengetahui daerahdaerah yang mengalami peningkatan. Oleh karena itu, pada tugas akhir ini dibuat aplikasi OLAP berbasis spasial yang menghasilkan informasi strategis, serta memberikan gambaran analisa data sesuai kebutuhan pengguna dalam meningkatkan hasil usaha di Koperasi Sehati depok. Berdasarkan dari uji coba yang dilakukan dengan menggunakan metode OLAP, didapatkan berbagai informasi yang dapat dilihat dari berbagai sudut pandang. Operasi-operasi OLAP seperti slicing, dicing, roll up dan drill down yang telah dilakukan uji coba juga menghasilkan informasi dari berbagai sudut pandang yang sesuai dengan kebutuhan manajeman.
\end{abstract}

Kata Kunci-Koperasi, OLAP, Data Warehouse, Sistem Informasi Geografis.

\section{PENDAHULUAN}

$\mathrm{K}^{\mathrm{o}}$ OPERASI indonesia adalah badan usaha yang beranggotakan orang-orang, seseorang, atau badan hukum koperasi dengan melandaskan kegiatannya berdasarkan prinsip koperasi, sekaligus sebagai gerakan ekonomi rakyat yang berdasarkan asas kekeluargaan. Istilah koperasi diatas termuat dalam Undang-Undang No. 25 tahun 1992 pasal 1 ayat 1 tentang perkoperasian[1]. Koperasi sebagai badan usaha yang bertujuan untuk memajukan kesejahteraan anggotanya, seringkali dipakai oleh pihak perusahan dibidang IT khususnya pada pengelolaan data-data koperasi dalam menentukan kemajuan hasil usahanya tersebut. Pada artikel ini data yang digunakan adalah data transaksi booking dari Koperasi Sehati Depok yang dikelola oleh perusahan PT. Prawathiya Karsa Pradiptha. Data transaksi booking tersebut menghasilkan berbagai informasi yang strategis dan digunakan sebagai analisis sesuai dengan kebutuhan pengguna khususnya bagian manajemen.

OLAP (On-Line Analytical Processing) merupakan salah satu metode yang paling efektif untuk menentukan kebutuhan pengolahan data transaksi booking yang dijadikan sebagai berbagai informasi. Karena data transaksi booking yang ada pada OLAP tersebut disimpan dalam bentuk multidimensi (dapat dilihat dari berbagai sudut pandang) yang tidak seperti pada basis data relasional. Selain itu, OLAP juga menyediakan beberapa operasi yang berguna untuk mengekplorasi hasil informasi apa saja yang didapat dari data sumber transaksi booking. Seperti slice \& dice, roll up, dan drill down, dimana operasi tersebut dapat menghasilkan informasi dari berbagai sudut pandang yang berbeda.

Informasi terkait data spasial juga sangat diperlukan dalam pembuatan aplikasi OLAP berbasis Spasial ini. Karena tingkat kemajuan suatu koperasi dilihat dari banyaknya customer yang melakukan proses transaksi pada koperasi pusat atau cabang dari koperasi tersebut. Sering kali analisa pada data spasial ditunjukkan dalam bentuk titik lokasi pada peta. Salah satu contohnya, penentuan tata letak suatu perusahaan atau cabang perusahaan dilihat dari segi banyaknya costumer yang melakukan transaksi. Dapat dilihat dari banyaknya customer tersebut mengakibatkan perusahaan atau cabang perusahaan diwilayah tertentu itu mengalami keuntungan yang banyak.

Pada penelitian yang dilakukan oleh Sandro Bimonte mengembangkan aplikasi untuk menangani daerah rawan banjir di Kota Marseille dan Lyon[2]. Aplikasi tersebut menggunakan proses OLAP dan Sistem informasi geografis dalam penyajian informasinya, serta terfokus untuk mengintegrasikan sistem OLAP dan sistem informasi geografis. Sehingga dapat menampilkan pemetaan yang lebih akurat dalam menangani daerah rawan banjir. Penelitian yang sama dengan menggunakan metode OLAP juga dilakukan oleh Maulana Bhara Haningtyas yaitu pembuatan aplikasi OLAP untuk sistem informasi geografis daerah rawan kasus narkoba di kota Surabaya[3]. Penelitian lainnya dalam suatu koperasi yaitu pembuatan data warehouse pada Koperasi Anugerah Rejeki yang disusun oleh Khaerur Rizki[4]. Selain itu, ada juga beberapa penelitian terkait data spasial yaitu penelitian yang dilakukan oleh Budi Setiyono dan Imam Mukhlash[5], serta Suharmadi[6]. Penelitian tersebut meneliti tentang Algoritma GBScan, Clarans, dan cure untuk spasial clustering, serta pemodelan kualitas air tanah.

Oleh karena itu, dalam tugas akhir ini telah dilakukan pembuatan aplikasi OLAP berbasis spasial untuk memperoleh berbagai informasi yang dapat digunakan sebagai analisis. Selain itu, didapatkan juga informasi terkait spasial dalam menentukan daerah-daerah yang mengalami peningkatan kemajuan hasil usaha di Koperasi Sehati Depok.

\section{TINJAUAN PUSTAKA}

\section{A. Data Warehouse}

Data warehouse adalah kumpulan suatu data dari berbagai open source yang berbeda-beda dengan format dan jenis data yang berbeda pula. Data warehouse juga telah 
mengalami pengolahan data dan dikumpulkan dalam suatu penyimpanan yang ukurannya besar sehingga dapat digunakan untuk pengambilan keputusan. Menurut Bill Inmon karakteristik data warehouse yaitu Subject Oriented, Integrated, Time Variant dan Non-Volatile[8]. Dalam pembuatan data warehouse terdapat proses ETL (Extraction, Transformation, dan Loading)[9] yang terdapat pada staging area.

\section{B. OLAP}

On-Line Analytical Processing atau yang biasa disebut OLAP adalah sebuah metode yang memungkinkan untuk melihat data dari berbagai sudut pandang[9]. OLAP memungkinkan pengguna akhir untuk melakukan analisis data dalam beberapa dimensi, sehingga memberikan wawasan dan pemahaman yang mereka butuhkan untuk membuat keputusan yang lebih baik. Operasi-operasi yang terdapat pada OLAP antara lain slicing, dicing, roll-up, dan drill-down.

1) Slicing

Slicing dan dicing adalah operasi untuk melihat data sebagai visualisasi dari cube. Dimana slicing merupakan proses pemotongan salah satu sisi dari cube (sub cube), sehingga diperoleh suatu informasi berdasarkan kategori tertentu.

2) Dicing

Dicing adalah proses pemilihan informasi dari data pada data 2 dimensi atau lebih, sehingga informasi yang didapat bisa dianalisis secara spesifik.

3) Roll-Up

Roll up adalah proses generalisasi satu atau beberapa dimensi dengan merangkum atau meringkas nilai-nilai ukurannya, sehingga dapat ditentukan informasi secara umum.

\section{4) Drill-Down}

Drill down adalah proses memilih atau menampilkan rincian data dalam satu atau beberapa dimensi dan merupakan kebalikan dari roll up, sehingga dapat digunakan untuk menjawab suatu pertanyaan yang diberikan

\section{Sistem Informasi Geografis}

Sistem Informasi Geografis adalah suatu sistem untuk menghasilkan pengolahan dan analisis data spasial serta data non-spasial, dalam memperoleh berbagai informasi yang berkaitan dengan aspek keruangan, baik yang berorientasi ilmiah, komersil, pengelolaan maupun kebijaksanaan[10]. Dalam pembuatan sistem informasi geografis sering kali menggunakan Google Maps API. Google Maps API (Application Programing Interface) adalah suatu library yang berbentuk JavaScript, yang berisi fungsi-fungsi pemrograman yang disediakan oleh Google maps agar Google Maps bisa di integrasikan kedalam Web atau aplikasi yang sedang di buat[11].

\section{METODOLOGI PENELITIAN}

\section{A. Sumber Data}

Sumber data yang digunakan dalam penelitian ini adalah data transaksi booking yang mana merupakan nama suatu projek yang dikelola oleh perusahaan konsultan IT PT. Prawathiya Karsa Pradiptha (PT. PKP) atas data-data dari Koperasi Sehati. PT. PKP adalah perusahaan yang bergerak di bidang bisnis informatika yang menggunakan jasa atau layanan yang ditawarkan untuk membantu dalam hal pengambilan keputusan yang tepat dengan menggabungkan dan menerapkan teknologi dan layanan yang terbaru. Data transaksi booking berisi data-data yang diantaranya terkait pembiayaan dalam Koperasi Sehati. Dalam penelitian ini data transaksi booking dibagi menjadi 2 data yaitu data nonspasial dan data spasial. Data non-spasial dari data transaksi booking dijadikan data warehouse dan kemudian dijadikan data multidimensi dengan menggunakan metode OLAP. Sedangkan data spasial diperoleh dari data lokasi outlet dan lokasi alamat customer pada data transaksi booking yang dibentuk titik-titik koordinat pada peta.

\section{B. Peralatan}

\section{1) Perangkat Keras (Hardware)}

a. Laptop

b. Printer

2) Perangkat Lunak (Software)

a. Interface berbasis web menggunakan $P H P$

b. DBMS yang digunakan adalah $M y S Q L$ dari $X A M P P$

c. Google Maps API yang digunakan untuk memenuhi kebutuhan data spasial

d. Highchart API yang digunakan untuk memenuhi kebutuhan grafik

e. Pentaho Data Integration yang digunakan untuk cek pengujian data multidimensi

f. Microsoft Office untuk pembuatan laporan

3) Tahapan Pengolahan Data

Tahapan pengolahan data pada penelitian ini dapat dilihat pada Gambar 1. Blok diagram penelitian dibawah ini.

\section{Analisa Kebutuhan Sistem}

1. Mampu menampilkan informasi jumlah transaksi booking per bulan dan pertahun dalam bentuk spasial ditinjau dari beberapa sudut pandang yaitu :

a) Lokasi koperasi berdasarkan wilayah dan outlet

b) Barang jaminan, yaitu tahun BPKB sepeda motor yang digunakan sebagai jaminan

c) Customer dengan latar belakang pekerjaaan

2. Mampu menampilkan berbagai informasi strategis dari data Transaksi Booking berdasarkan informasi terkait dengan pelaporan yang diinginkan, seperti :

a) Menampilkan data booking

b) Menampilkan jumlah data booking

c) Menampilkan rangking jumlah booking dari yang terbesar sampai terkecil

d) Menampilkan rangking total amount pinjaman

e) Menampilkan komposisi collateral (jaminan) berdasarkan tipe motor

f) Menampilkan report compare (perbandingan) dalam setiap bulan

g) Menampilkan total jumlah booking

h) Menampilkan report perbandingan achievement dengan target (target total jumlah booking)

i) Menampilkan report perbandingan achievement dengan target (target total amount pinjaman)

3. Mampu menampilkan informasi dalam bentuk spasial sehingga dapat digunakan sebagai acuan dalam mempertimbangkan suatu gambaran analisis kebutuhan. Informasi tersebut dapat dilihat dari jumlah customer pada daerah persekitaran terjadinya transaksi booking di cabang Koperasi Sehati Depok yang sesuai target. 

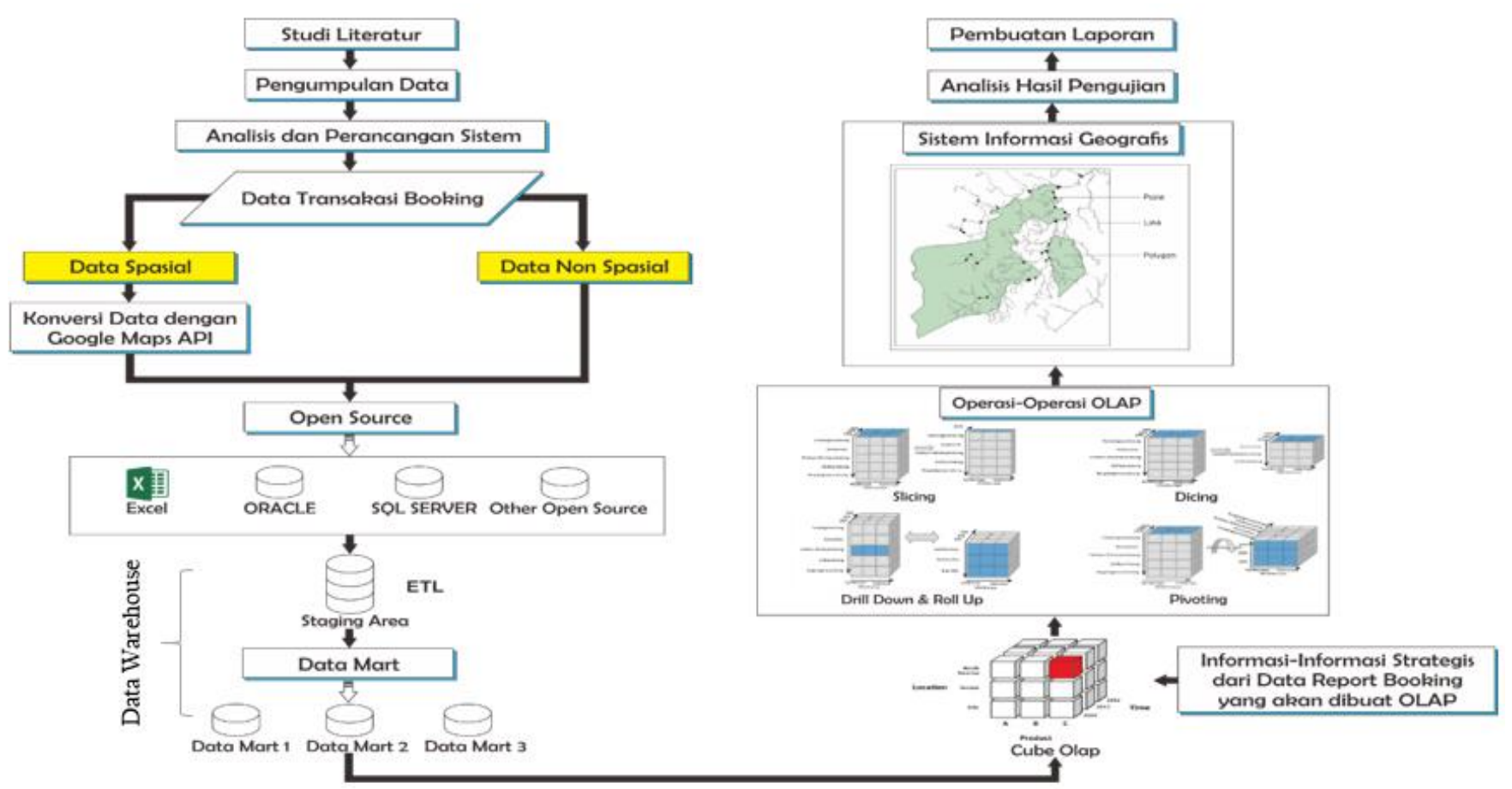

Gambar 1. Blok diagram OLAP berbasis Spasial.

\section{ANALISIS DAN PEMBAHASAN}

\section{A. Operasi-Operasi OLAP}

\section{1) Dicing}

Operasi dicing adalah operasi pengambilan data berdasarkan beberapa sudut pandang dari cube OLAP yang lebih dari satu. Berikut hasil operasi dicing pada data transaksi booking di Koperasi Sehati Depok.

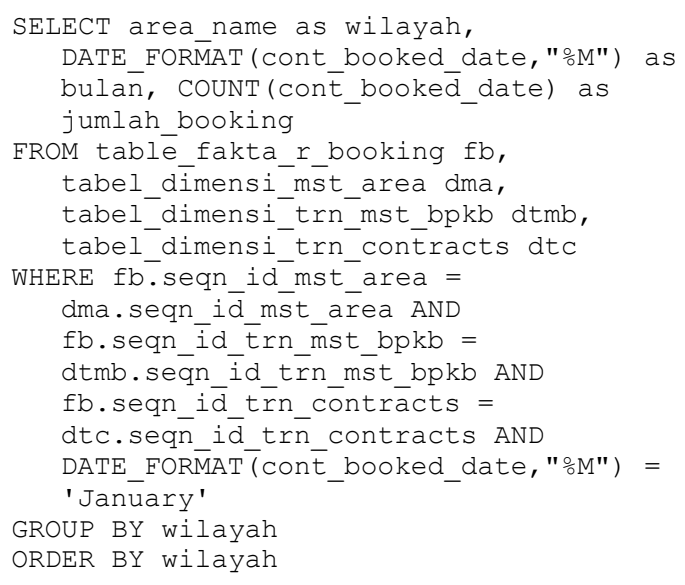

Tabel 1.

Hasil Operasi Dicing

\begin{tabular}{lcc}
\hline \hline Wilayah & Bulan & Jumlah Booking \\
\hline BANTEN-1 & January & 36 \\
BENGKULU-1 & January & 73 \\
BENGKULU-2 & January & 92 \\
JAWA BARAT-1 & January & 160 \\
JAWA BARAT-2 & January & 184 \\
KALIMANTAN & January & 265 \\
LAMPUNG & January & 172 \\
NUSA TENGGARA BARAT & January & 70 \\
SUMATERA SELATAN-2 & January & 150 \\
SUMATERA SELATAN-3 & January & 326 \\
\hline \hline
\end{tabular}

Dari Tabel 1. menunjukkan hasil operasi Dicing dengan menggunakan sudut pandang di setiap wilayah pada Koperasi
Sehati di bulan januari 2017 dalam menentukan informasi banyak jumlah booking.

2) Slicing

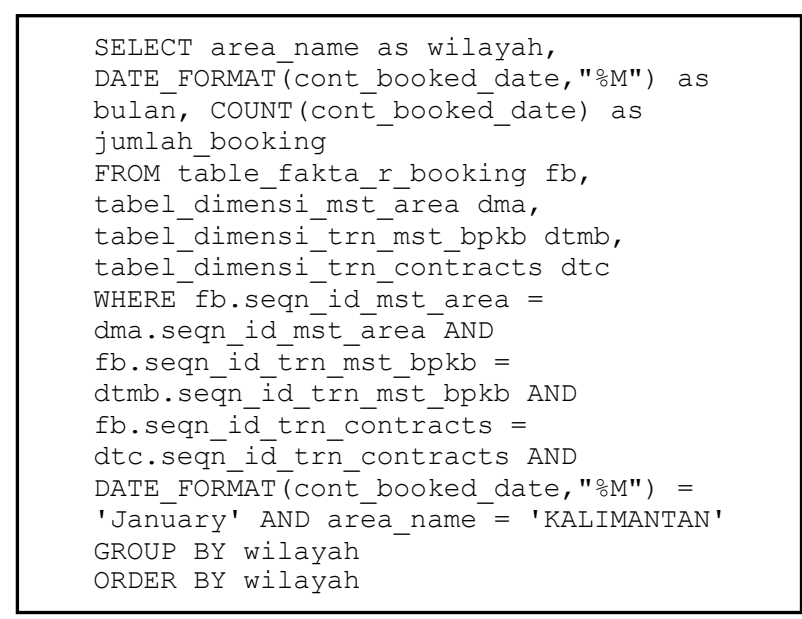

Tabel 2.

Hasil Operasi Slicing

\begin{tabular}{lcc}
\hline \hline Wilayah & Bulan & Jumlah Booking \\
\hline KALIMANTAN & January & 265 \\
\hline \hline
\end{tabular}

Operasi slicing adalah pengambilan data pada operasi dicing yang berdasarkan sisi sudut pandang yang sama dari cube OLAP. Berikut hasil operasi slicing pada data transaksi booking di Koperasi Sehati Depok.

Dari Tabel 2. menunjukkan hasil operasi slicing dari pengambilan sebagian data operasi dicing. Dimana menghasilkan informasi jumlah booking yang terjadi di wilayah KALIMANTAN pada bulan januari 2017.

3) Roll-Up

Operasi roll-up adalah proses generalisasi satu atau beberapa sudut pandang dengan merangkum atau meringkas nilai-nilai ukurannya, sehingga dapat ditentukan informasi secara umum. Berikut hasil operasi roll-up pada data transaksi bookingdi Koperasi Sehati Depok. 


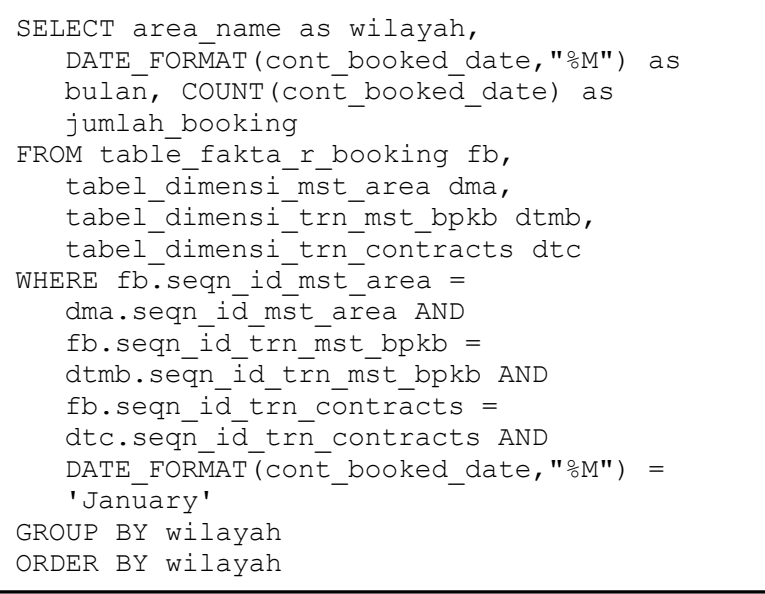

Tabel 3.

Hasil Operasi Roll-Up

\begin{tabular}{lcc}
\hline \hline Wilayah & Bulan & Jumlah Booking \\
\hline BANTEN-1 & January & 36 \\
BENGKULU-1 & January & 73 \\
BENGKULU-2 & January & 92 \\
JAWA BARAT-1 & January & 160 \\
JAWA BARAT-2 & January & 184 \\
KALIMANTAN & January & 265 \\
LAMPUNG & January & 172 \\
NUSA TENGGARA BARAT & January & 70 \\
SUMATERA SELATAN-2 & January & 150 \\
SUMATERA SELATAN-3 & January & 326 \\
\hline \hline
\end{tabular}

Hasil dari Tabel 3. menunjukkan hasil operasi roll-up dengan menggunakan sudut pandang seluruh wilayah pada Koperasi Sehati di bulan januari-februari 2017 dalam menentukan informasi banyak jumlah booking tiap wilayah. Dapat dilihat pada Tabel 3. Yang berwarna kuning sebagai contoh dari hasil operasi roll-up ini.

\section{4) Drill-Down}

Operasi drill down adalah operasi proses memilih atau menampilkan rincian data dalam satu atau beberapa dimensi dan merupakan kebalikan dari roll-up, sehingga dapat digunakan untuk menjawab suatu pertanyaan yang diberikan. Berikut hasil operasi drill-down pada data transaksi booking di Koperasi Sehati Depok.

Hasil dari Tabel 4. menunjukkan hasil operasi drill-down yang menampilkan rincian data dari operasi roll-up dengan mengambil sudut pandang wilayah BANTEN-1 dan BENGKULU-1, serta sudut pandang di setiap pekerjaan customer pada bulan januari 2017 dalam menentukan banyak jumlah booking.

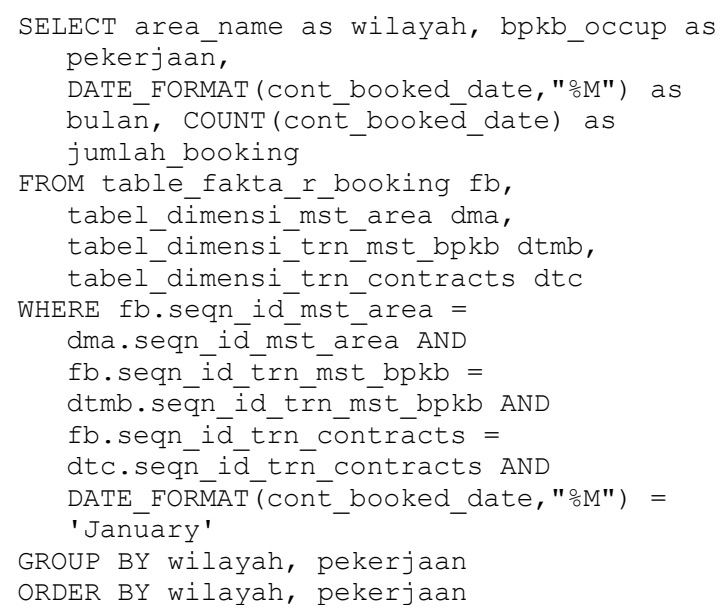

Tabel 4.

Hasil Operasi Drill-Down

\begin{tabular}{lllc}
\hline \hline \multicolumn{1}{c}{ Wilayah } & \multicolumn{1}{c}{ Pekerjaan } & Bulan & $\begin{array}{c}\text { Jumlah } \\
\text { Booking }\end{array}$ \\
\hline BANTEN-1 & BELUM / TIDAK & January & 4 \\
& BEKERJA & & \\
BANTEN-1 & IRT & January & 1 \\
BANTEN-1 & KARYAWAN & January & 15 \\
BANTEN-1 & MAHASISWA / & January & 4 \\
& PELAJAR & & \\
BANTEN-1 & MRT & January & 5 \\
BANTEN-1 & PNS & January & 1 \\
BANTEN-1 & WIRASWASTA / & January & 6 \\
& PEDAGANG & & \\
BENGKULU-1 & BELUM / TIDAK & January & 8 \\
& BEKERJA & & \\
BENGKULU-1 & BHL & January & 4 \\
BENGKULU-1 & IMAM MASJID & January & 1 \\
BENGKULU-1 & IRT & January & 2 \\
BENGKULU-1 & KARYAWAN & January & 4 \\
BENGKULU-1 & MAHASISWA / & January & 5 \\
& PELAJAR & & \\
BENGKULU-1 & MRT & January & 2 \\
BENGKULU-1 & PERANGKAT DESA & January & 1 \\
BENGKULU-1 & PETANI / PEKEBUN & January & 28 \\
BENGKULU-1 & PNS & January & 2 \\
BENGKULU-1 & SOPIR & January & 1 \\
BENGKULU-1 & TUKANG KAYU & January & 1 \\
BENGKULU-1 & WIRASWASTA / & January & 14 \\
& PEDAGANG & & \\
\hline \hline
\end{tabular}

\section{B. Informasi sebagai Analisis}

Pada data transaksi booking di Koperasi Sehati Depok ditentukan target pengklasifikasian outlet dengan melihat dari informasi jumlah total booking dan jumlah total pinjaman peroutlet untuk mengetahui kemajuan usaha di koperasi tersebut. Sehingga pada artikel ini hanya ditampilkan informasi-informasi yang digunakan sebagai analisis bisnis yaitu terhadap outlet-outlet yang sesuai dengan target yang ditentukan.

Tabel 5.

Jenis Target Peroutlet

\begin{tabular}{clcc}
\hline \hline No & Jenis Target & Jumlah Total Booking & Jumlah Total Pinjaman \\
\hline 1 & Small & 100 & Rp. 1.000 .000 .000 \\
2 & Medium & 125 & Rp. 2.000 .000 .000 \\
3 & Big & 150 & Rp. 2.500 .000 .000 \\
\hline \hline
\end{tabular}

Berikut ditampilkan informasi dari target peroutlet dalam bentuk grafik dan peta.

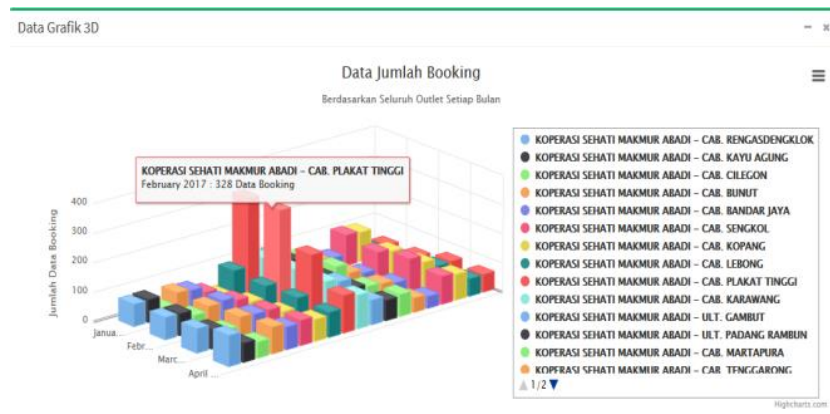

Gambar 2. Tampilan grafik target outlet perbulan berdasarkan jumlah data booking.

Pada Gambar 2. diatas dapat dilihat jumlah data booking terbanyak dalam setiap bulan terdapat pada outlet Koperasi Sehati Makmur Abadi - Cabang Plakat Tinggi pada bulan Februari yaitu sebesar 328 data booking. 


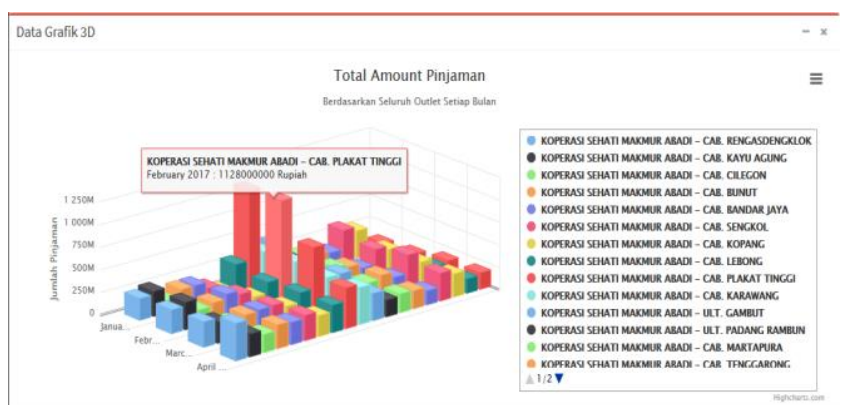

Gambar 3. Tampilan grafik target outlet perbulan berdasarkan jumlah total pinjaman.

Pada Gambar 3. dapat dilihat jumlah total pinjaman terbanyak dalam setiap bulan terdapat pada outlet Koperasi Sehati Makmur Abadi - Cabang Plakat Tinggi pada bulan Februari yaitu sebesar Rp. 1.128.000.000,-.

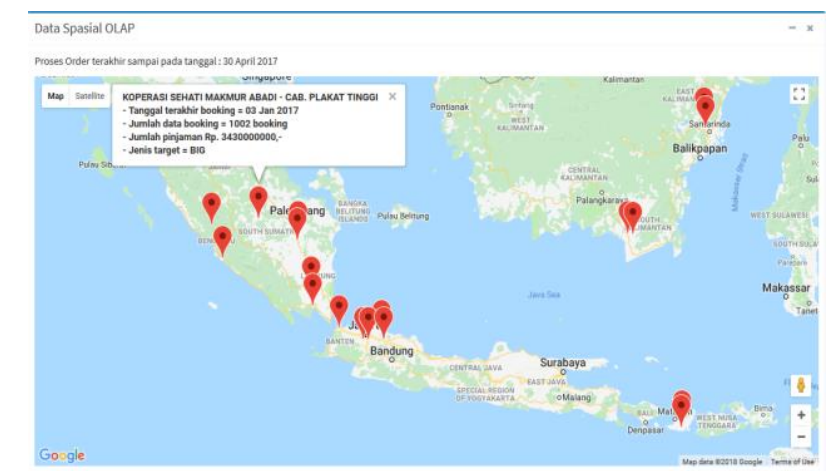

Gambar 4. Tampilan peta target outlet secara keseluruhan.

Pada Gambar 4. dapat dilihat target outlet secara keseluruhan yang memenuhi target dengan jenis target terbesar yaitu terdapat pada outlet Koperasi Sehati Makmur Abadi Cabang Plakat Tinggi dengan jumlah data booking sebesar 1002 data booking, jumlah total pinjaman sebesar Rp. 3.430.000.000, dan jenis targetnya adalah Big.

\section{Pembuatan Daerah Persekitaran}

Data spasial dalam data transaksi booking dibuat daerah persekitaran dalam yang mana dalam penelitian ini dilakukan untuk mengetahui data customer yang melakukan transaksi di berbagai outlet Koperasi Sehati Depok. Analisa pembuatan daerah persekitaran ini dimulai dari penentuan dalam radius 5 kilometer dan 1 mile meter pada lokasi outlet. Kemudian dari radius tersebut dilihat berapa banyak customer yang melakukan transaksi pada persekitaran outlet tersebut. Berikut analisa dari pembuatan daerah persekitaran outlet dalam radius 5 kilometer dan 5 mile.

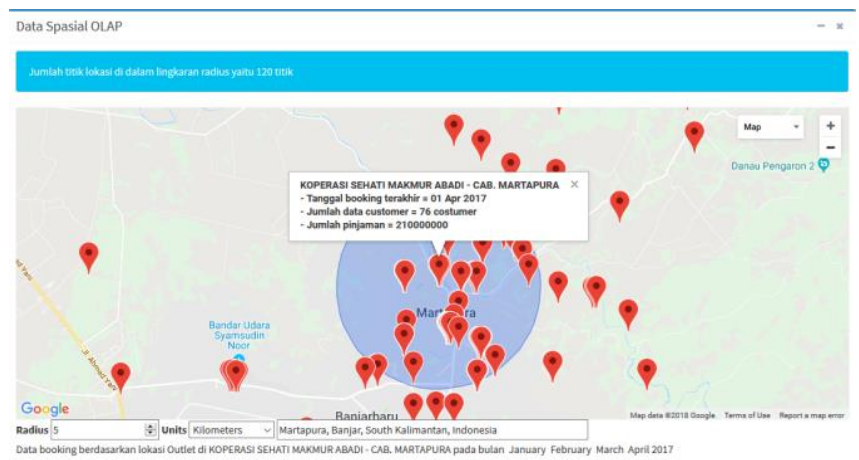

Gambar 5. Tampilan hasil pembuatan daerah persekitaran pada lokasi outlet Koperasi Sehati Makmur Abadi - Cabang Martapura dalam radius 5 kilometer
Pada Gambar 5. dilakukan pembuatan daerah persekitaran dengan radius 5 kilometer dari salah satu titik di lokasi Outlet yaitu di Koperasi Sehati Makmur Abadi - Cabang Martapura. Terlihat bahwa dipersekitaran daerah yang mencangkup radius 5 kilometer terdapat masjid, alun-alun, rumah sakit, sekolah dan tempat umum lainnya. Pada daerah persekitaran outlet tersebut terdapat 120 data customer yang melakukan transaksi pada radius 5 kilometer.

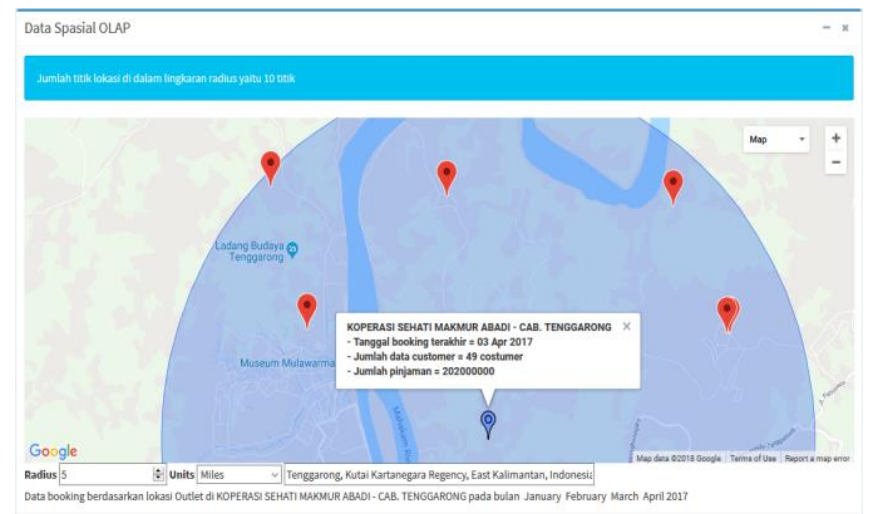

Gambar 6. Tampilan hasil pembuatan daerah persekitaran pada lokasi outlet Koperasi Sehati Makmur Abadi - Cabang Tenggarong dalam radius 5 mile

Pada Gambar 6. diatas dilakukan pembuatan daerah persekitaran dengan radius 5 mile dari salah satu titik di lokasi Outlet yaitu Koperasi Sehati Makmur Abadi - Cabang Tenggarong. Terlihat bahwa dipersekitaran daerah yang mencangkup radius 5 mile terdapat obyek wisata, museum, sungai, ladang budaya dan tempat umum lainnya. Dari daerah persekitaran outlet tersebut terdapat 10 data customer yang melakukan transaksi pada radius 5 mile.

\section{KESIMPULAN DAN SARAN}

\section{A. Kesimpulan}

Penggunaan operasi-operasi olap seperti Slicing, Dicing, Roll Up dan Drill down dari aplikasi OLAP berbasis Spasial pada data transaksi booking didapatkan berbagai informasi yang dibutuhkan pengguna khususnya bagi para manjemen. Karena data yang dihasilkan berbentuk multidimensi dapat dilihat dari berbagai sudut pandang, sehingga mempermudah untuk melakukan analisis bisnis untuk peningkatan hasil usaha di Koperasi Sehati Depok.

Secara keseluruhan jumlah data booking di Koperasi Sehati Depok mengalami peningkatan dan penurunan. Pada bulan Januari 2017 terdapat 1498 data booking dan mengalami peningkatan sebesar $3 \%$ pada bulan Februari 2017. Kemudian pada bulan Maret 2017 terjadi penurunan sebesar $0.9 \%$ dari bulan sebelumnya dan mengalami peningkatan lagi sebesar 0.1\% pada Bulan April 2017.

Dari hasil uji coba aplikasi OLAP berbasis Spasial dari data transaksi booking di Koperasi Sehati Depok menunjukkan bahwa jumlah data booking terbanyak secara keseluruhan selama bulan Januari - April 2017 ditinjau dari outlet yaitu di Koperasi Sehati Makmur Abadi - Cabang Plakat Tinggi sebesar 1002 data booking. Sedangkan untuk jumlah pinjaman terbanyak secara keseluruhan selama bulan Januari-April 2017 dilakukan di outlet Koperasi Sehati Makmur Abadi - Cabang Plakat Tinggi Wilayah Sumatera sebesar Rp. 3.430.000.000,-. Dimana pada outlet tersebut sudah memenuhi target yang telah ditentukan oleh pihak managemen yaitu dengan klasifkasi jenis "Big". 
Pada pembuatan daerah persekitaran menunjukkan bahwa lokasi outlet yang berpengaruh terhadap jumlah customer yang melakukan transaksi yaitu terdapat pada outlet Koperasi Sehati Makmur Abadi-Cabang Martapura, Sebulu dan Tenggarong. Dimana lokasi alamat customer yang melakukan transaksi booking berada dipersekitaran outletoutlet tersebut.

\section{B. Saran}

Data yang digunakan dalam pembuatan perangkat lunak masih dalam jangka waktu pendek yaitu pada bulan Januari 2017 - April 2017 dan data terkait spasial yang masih berupa data dummy. Sehingga, apabila digunakan data dalam jangka waktu 10 tahun dan data spasial yang tepat, maka akan diperoleh data yang lebih lengkap dan sesuai.

Proses pengolahan data terhadap abstrak dapat menggunakan metode lainnya sehingga diperoleh analisis bisnis yang lebih baik lagi.

\section{DAFTAR PUSTAKA}

[1] R. Indonesia, Undang-Undang NO. 25 Tahun 1992 tentang Perkoperasian. Indonesia, 1992.

[2] S. Bimonte, O. Boucelma, O. Machabert, and S. Sellami, “A new
Spatial OLAP approach for the analysis of Volunteered Geographic Information," Comput. Environ. Urban Syst., vol. 48, pp. 111-123, 2014.

[3] M. B. HANINGTYAS, Implementasi On-Line Analytical Processing (OLAP) pada Sistem Informasi Geografis untuk Daerah Rawan Kasus Narkoba di Surabaya. Surabaya: POMITS, 2017.

[4] K. Rizki, "Penerapan Data Warehouse Pada Koperasi Anugerah Rejeki," in Perpustakaan UNIKOM, Bandung: Perpustakaan UNIKOM, 2016.

[5] B. Setiyono and I. Mukhlash, "Kajian Algoritma GDBScan Clarans dan Cure untuk Spatial Clustering," Limits, vol. 2, no. 2, pp. 117-128, 2005.

[6] Suharmadi, "Pemodelan Kualitas Air Tanah," Limits, vol. 1, no. 1, pp. 37-40, 2004.

[7] W. H. Inmon, Building the Data Warehouse : Getting Started, 3rd ed. Canada: Wiley, 2002.

[8] V. Rainardi, Building a Data Warehouse : With Examples in SQL Server. New York: Apress, 2007.

[9] A. Berson and S. J. Smith, Data warehousing, data mining, and OLAP. New York: McGraw-Hill, 1997.

[10] M. Hanafi, SIG dan AHP untuk Sistem Pendukung Keputusan Perencanaan Wilayah Industri dan Pemukiman Kota Medan Medan: Universitas Sumatera Utara, 2011.

[11] A. Fauzan, "Google Maps API : Teori Pengantar, Mendapatkan Key dan Penggunaannya Pada Web," 2015. [Online]. Available: http://www.charisfauzan.net/2015/09/google-maps-api-teoripengantar.html. [Accessed: 24-Sep-2015]. 